\title{
Agôn
}

Revue des arts de la scène

Critiques | Saison 2013-2014

\section{Scènes de la vie conjugale, Tg STAN}

À la lisière du théâtre

\section{Alice Carré}

\section{Q OpenEdition}

\section{Journals}

Édition électronique

URL : http://journals.openedition.org/agon/2910

DOI : 10.4000/agon.2910

ISSN : 1961-8581

Éditeur

Association Agôn

Référence électronique

Alice Carré, "Scènes de la vie conjugale, Tg STAN », Agôn [En ligne], Critiques, mis en ligne le 02 mars 2014, consulté le 23 septembre 2020. URL : http://journals.openedition.org/agon/2910 ; DOI : https:// doi.org/10.4000/agon. 2910

Ce document a été généré automatiquement le 23 septembre 2020

Association Agôn et les auteurs des articles 


\section{Scènes de la vie conjugale, Tg STAN}

À la lisière du théâtre

\section{Alice Carré}

\section{RÉFÉRENCE}

Scènes de la vie conjugale, Texte d'Ingmar Bergman, mise en scène du collectif tg STAN

Théâtre de la Bastille, du 11 au 22 février 2014

On l'avait vu il y a quelques années à la Comédie Française lorsque la troupe s'était essayée à l'exercice, la « manière » tg STAN n'est pas aisément transmissible. Il y a chez Frank Vercruyssen et Ruth Vega Fernandez un savoir-faire inexplicable, une façon de jouer sur l'arête entre le jeu et le non-jeu, comme si rien n'était jeu et comme si tout l'était. La crête est étroite, le pied risque à tout moment de déraper d'un côté ou de l'autre, le corps de basculer. Et c'est justement cette zone d'instabilité permanente, ces glissements, qui font que rien n'est jamais figé, que tout reprend une nécessité première et que chaque geste se re-questionne à la lisière du théâtre. 


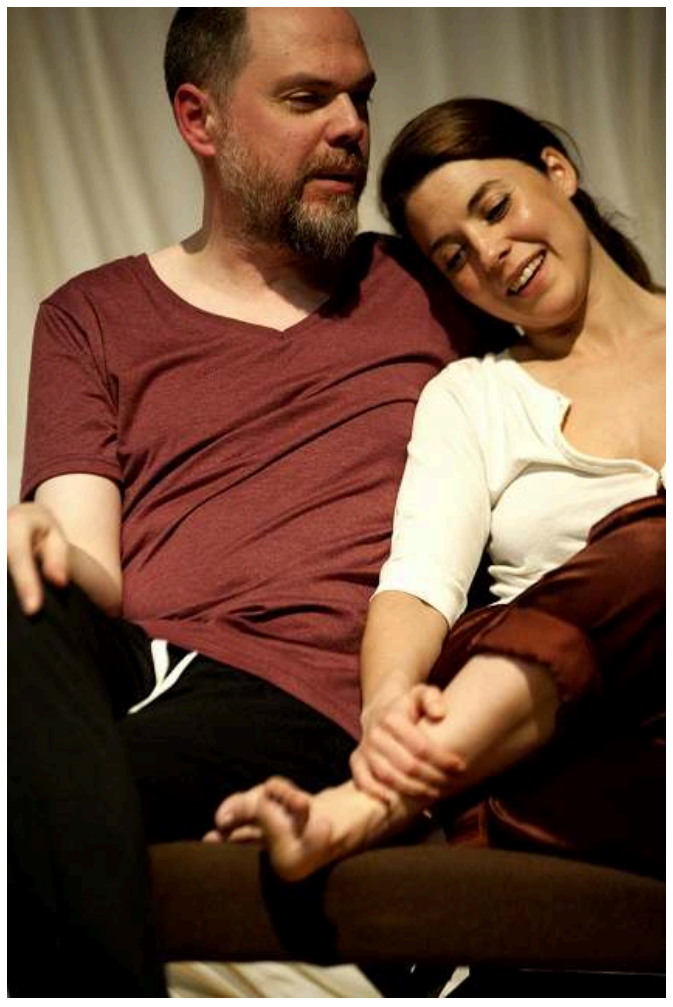

(c) Dylan Piaser

2 L'entrée dans la matière du film de Bergman, Scènes de la vie conjugale, se fait aussi naturellement que si Bergman n'était pas Bergman, sans s'embarrasser d'un respect outrancier et paralysant, mais avec humour, finesse et intelligence. Le film devient matière à jouer, qui fait penser au célèbre aphorisme d'Antoine Vitez : «On peut faire théâtre de tout ». Le cinéma est bien là pourtant, cité à travers la projection sur grand écran d'une scène de dîner entre couples où le ménage uni de Marianne et Johann assiste à la déliquescence du mariage de leurs amis. L'amour s'effrite et l'union éclate, c'est presque inévitable et structurel, et c'est au spectacle du craquellement de ce foyer apparemment comblé que nous convient les acteurs. Cet échec de la vie à deux et ces caprices de l'amour nous sont livrés à travers les sursauts d'un théâtre sans illusion, sans drame, sans dérision forcée, sans faire semblant. Si l'émotion devient trop pathétique, d'un revers de main, les comédiens la délogent et la désacralisent. Ils se barbouillent le visage de maquillage pour dire les saignements d'un corps à corps enragé ; ils s'arrêtent au milieu d'un faux coup de pied et nous disent qu'ils ne peuvent pas le faire pour de vrai pour ne pas tacher le tapis « parce qu'il faut qu'on joue demain soir »; ils reprennent la réplique d'avant quand ils se sont trompés en s'excusant pour leur «trou ». Et pourtant, dans ces interstices, dans ce "on reprend" émerge la justesse des émotions. On en arrive au point paradoxal de ce déséquilibre : en avouant que tout est théâtre, on fait son éloge en même temps qu'on le brise. Tout est vrai alors, puisque tout est faux. Rien ne nous différencie des acteurs et tout devient limpide, Marianne et Johann c'est eux autant que nous. Ils nous renvoient à nos propres échecs sentimentaux, à nos ratages amoureux, à nos tromperies et nos regrets, à nos rancœurs et nos désirs. La femme délaissée, l'homme en quête d'une nouvelle jeunesse, le désir 
renaissant quand l'objet lui échappe, l'adultère comme recommencement. L'échec en partage, l'amour en lieu commun, cette histoire à se distribuer entre nous.

3 Sur ce plateau à tout faire, penderies, accessoires et buffet sont dressés pour servir ce jeu à volonté. On a peur un jour de se lasser, de se dire qu'on connaît déjà les procédés, et pourtant, cette façon tg STAN bien connue apparaît comme une mine inépuisable, comme une malle dans laquelle piocher sans cesse un nouveau déguisement pour tout recommencer. De quoi nous faire oublier le jeu empesé de notre tradition classique à la française et le dépoussiérer. 